\title{
Multi-moving Loads Induced Vibration of FG Sandwich Beams Resting on Pasternak Elastic Foundation
}

\author{
Wachirawit SONGSUWAN ${ }^{1}$, Monsak PIMSARN ${ }^{1}$ and \\ Nuttawit WATTANASAKULPONG, ${ }^{2, *}$ \\ ${ }^{I}$ Department of Mechanical Engineering, Faculty of Engineering, King Mongkut's Institute of Technology \\ Ladkrabang, Bangkok 10520, Thailand \\ ${ }^{2}$ School of Engineering and Technology, Walailak University, Nakhon Si Thammarat 80160, Thailand
}

("Corresponding author’s e-mail: nuttawit.wa@wu.ac.th, nuttawit_mut@hotmail.com)

Received: 18 December 2019, Revised: 15 May 2020, Accepted: 12 June 2020

\begin{abstract}
The dynamic behavior of functionally graded (FG) sandwich beams resting on the Pasternak elastic foundation under an arbitrary number of harmonic moving loads is presented by using Timoshenko beam theory, including the significant effects of shear deformation and rotary inertia. The equation of motion governing the dynamic response of the beams is derived from Lagrange's equations. The Ritz and Newmark methods are implemented to solve the equation of motion for obtaining free and forced vibration results of the beams with different boundary conditions. The influences of several parametric studies such as layer thickness ratio, boundary condition, spring constants, length to height ratio, velocity, excitation frequency, phase angle, etc., on the dynamic response of the beams are examined and discussed in detail. According to the present investigation, it is revealed that with an increase of the velocity of the moving loads, the dynamic deflection initially increases with fluctuations and then drops considerably after reaching the peak value at the critical velocity. Moreover, the distance between the loads is also one of the important parameters that affect the beams' deflection results under a number of moving loads.
\end{abstract}

Keywords: FG sandwich beam, Free vibration, Forced vibration, Multi-moving loads, Elastic foundation

\section{Introduction}

Sandwich structures are typically composed of multi-layers of high-strength face sheets and flexible core. Owing to outstanding properties in a high strength-to-weight ratio, the use of sandwich structures has grown rapidly in various engineering applications such as automotive, marine, and aerospace industries. The fundamental behavior and design for isotropic and composite sandwich structures were described in the comprehensive textbook of Vinson [1]. In recent years, the concept of functionally graded (FG) sandwich structures has been introduced to enhance structural performance over conventional sandwich structures, which always encounter serious problems of de-bonding and delaminating modes of failure at interface layers. The material properties of FG sandwich structures are changed gradually across the interfaces. Thus, the inter-laminar stresses between layers are eliminated.

The possibilities in reducing inter-laminar stresses and stress concentrations at the interfaces are the main advantages of FG sandwich structures. Therefore, many researchers have been focusing on studying FG sandwich structures' mechanical behavior subjected to static and dynamic loadings by using various theories and analysis techniques. However, most of the studies are limited to static bending, buckling, and vibration analyses of FG sandwich structures. Additionally, the studies on the dynamic response of FG sandwich structures under dynamic loading action are scarce. In the past few years, there are a number of investigations associated with such structures in different problems and scenarios. For example, Vo et al. 
http://wjst.wu.ac.th

[2] proposed a finite element model for vibration and buckling problems of FG sandwich beams. They also showed the relationship between fundamental natural frequency and the critical buckling load of the beams. Nguyen et al. [3] studied vibration and buckling of FG sandwich beams using higher-order shear deformation theory with a hyperbolic distribution of transverse shear stress. A quasi-3D theory was used to deal with static bending, buckling, and vibration problems of FG sandwich beams $[4,5]$. Tossapanon and Wattanasakulpong [6] developed numerical models based on the Chebyshev collocation method for buckling and vibration analysis of FG sandwich beams with classical and non-classical boundary conditions. Using the state space approach, Trinh et al. [7] also presented the frequency results of FG sandwich beams supported by combinations of classical and elastic restrained boundary conditions. Bui et al. [8] applied a truly mesh-free radial point interpolation method to solve forced vibration of FG sandwich beams under harmonic, Heaviside step, and transient loadings. In the case of FG sandwich plate and shell analyses, these structures have also attracted researchers' increasing attention, which can be seen in Refs. [9-18].

Moving load problems are important in mechanical vibration analysis and practical applications, e.g., guideways of equipment, overhead cranes, railroads, and bridges. While it is very rare for FG sandwich beams, numerous investigations regarding the dynamic response of beams with moving loads were found mostly for the beams made of functionally graded materials or called FG beams. In the case of FG beams carrying a moving point load, Şimşek and Kocatürk [19] presented natural frequencies and dynamic deflections of FG beams based on the Euler-Bernoulli beam theory. The Lagrange multiplier was used in this study. Nonlinear vibration analysis of FG beams under the moving load's action was examined and presented [20]. To consider FG beams axially under a moving load, Şimşek et al. [21] showed the beams' dynamic behavior with the influences of material distribution, the velocity of the load, and excitation frequency on the dynamic deflections of the beams. Moving load-induced vibration of bidirectional FG beams was reported [22,23]. It was found that the free and forced vibration responses of the beams are considerably influenced by the material gradient indexes of the two directions. A mixed Rayleigh Ritz-Differential quadrature (DQ) method was employed to discretize and solve the spatial partial and temporal derivatives in the problems of free and forced vibration of FG beams isotropic plates carrying moving load [24,25]. To include thermal effect on the beams' vibration behavior with moving load, this topic was considered by Wang and Wu [26] for axially FG beams and Tao et al. [27] for fiber metal laminated beams. For FG beams with their edge cracked, Yan et al. [28] presented the beams' dynamic response with an open edge crack under dynamic loading. The beams were subjected to a transverse load moving at a constant speed. In terms of the beams carrying moving mass, we can also find this topic in the open literature [29-33]. Additionally, Şimşek [34] proposed analytical and numerical solutions for the vibration of an embedded microbeam carrying a moving micro-particle. The modified couple stress theory was used to form the governing equation of motion in the study. More recently, dynamic analysis of advanced composite structures has been investigated continuously; for example, FG graphene oxide-reinforced composite beams [35,36], FG sandwich beams with porous core [37], FG nanobeams [38], FG plates, and FG single and multi-span FG porous beams [40]. As aforesaid literature survey, there is no investigation on the dynamic response of FG sandwich beams except for the study in [41] that showed the beams' dynamic deflections under the action of two successive moving loads.

According to the literature survey, it is found that a large volume of literature has investigated and focused mostly on static bending, buckling and vibration of FG sandwich beams. Therefore, this present study aims to investigate the dynamic response of FG sandwich beams under the action of multi-moving loads, and the beams are assumed to be placed on the Pasternak elastic foundation composing of Winkler and shear layer springs. The governing equation of motion based on Timoshenko beam theory is derived from Lagrange's equations. The developed model proposed in this study can be used for analyzing the dynamic behavior of beams under an arbitrary number of moving loads; hence, this model is useful for dynamic structural design. Many important effects such as layer thickness ratio, boundary condition, spring constants of the foundation, length to height or beam thickness ratio, velocity, phase angle, and excitation frequency of the loads on free and forced vibration results of FG sandwich beams are taken into an investigation. 
http://wjst.wu.ac.th

\section{FG sandwich beams}

Considering an FG sandwich beam, which is composed of three layers of functionally graded faces and homogenous core as shown in Figure 1, the top and bottom faces are at $z= \pm h / 2$ where $h$ is thickness in the $z$-axis, $L$ is length in the $x$-axis and $b$ is the width of the beam. In this figure, the beam is subjected to an arbitrary number of moving loads $\left(P_{i}\right)$ with the same constant velocity $\left(v_{p}\right)$. The distance between the loads is defined by parameter $(d)$. The position in the $x$-direction of any load is dependent on the velocity and time $(t)$ with this relation, $x_{p i}=\left[v_{p} t-(i-1) d\right]$.

Additionally, as shown in the cross-sectional areas, there are two main types of FG sandwich beams made of ceramic and metal phases: FG sandwich beams with homogenous soft and hardcore. In general, the ceramic phase has a larger value of Young's modulus and it is harder than metal phase. Therefore, for FG sandwich beam with homogenous hardcore, the faces should be made from FG material composing of the mixture of ceramic and metal phases in which the top and bottom faces are metal-rich and the material constituents are varied continuously and smoothly to ceramic-rich at the core. On the other hand, the beam with homogenous softcore, the pattern of material variations is reversed.

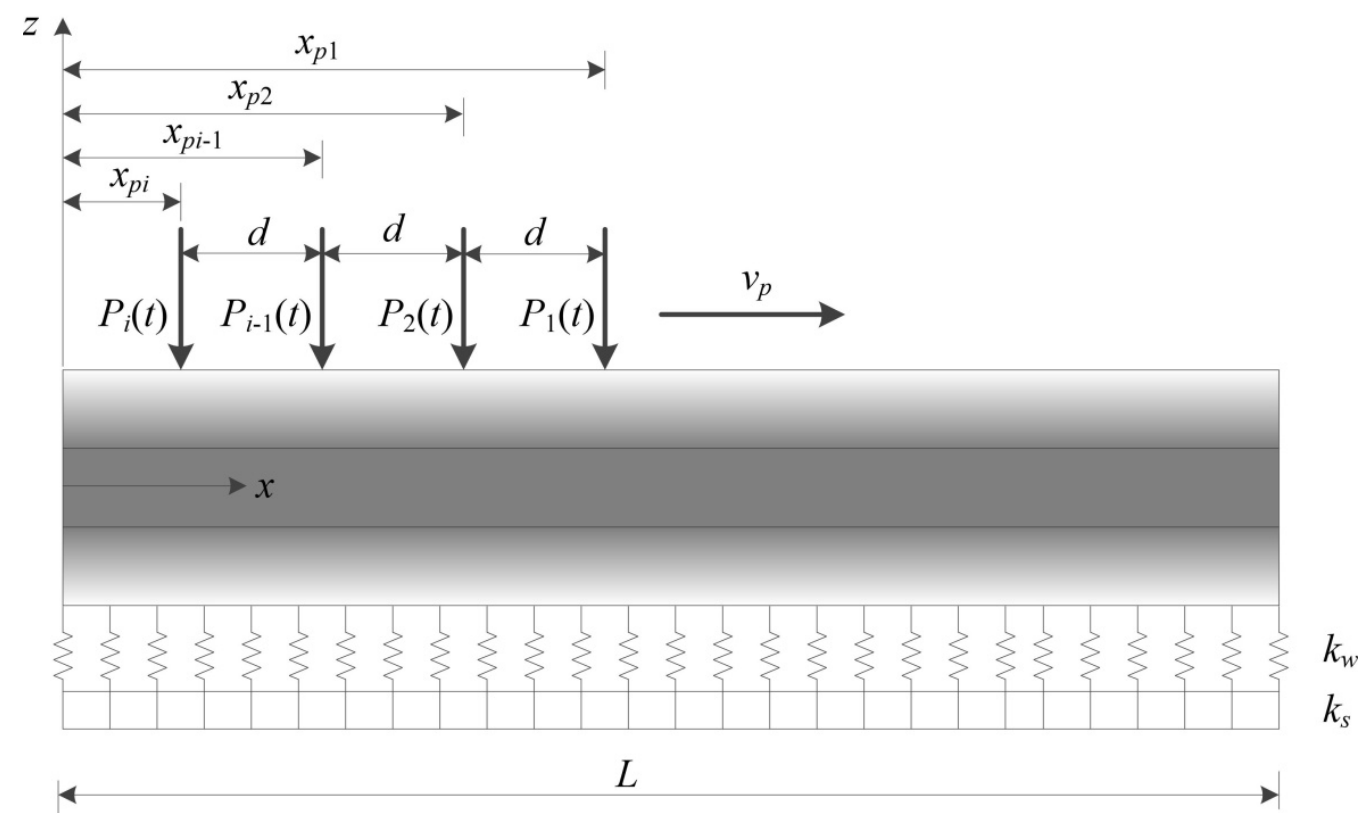

\section{Cross Section}

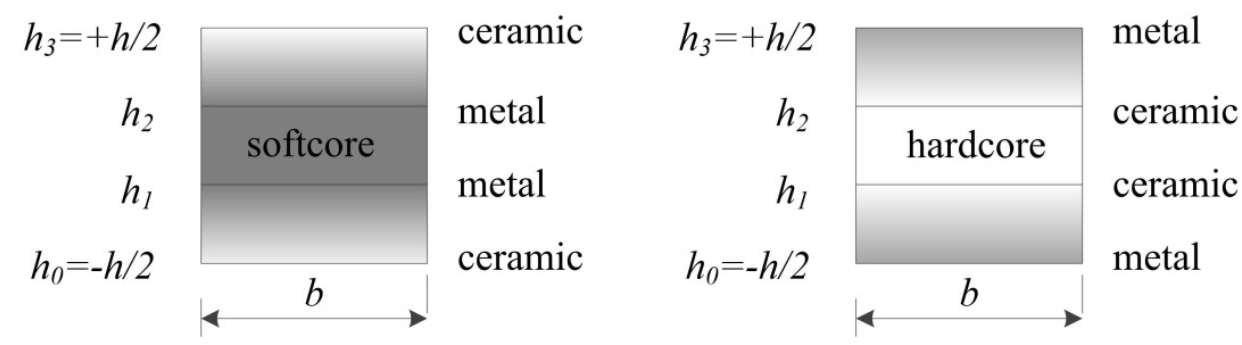

Figure 1 Geometry and coordinate of FG sandwich beam resting on elastic foundation under multimoving loads, $P_{i}(t)$, with constant $\left(v_{p}\right)$. 
http://wjst.wu.ac.th

The layer thickness ratio of the beam from the bottom $\left(z=h_{0}=-h / 2\right)$ to the top $\left(z=h_{3}=+h / 2\right)$ is defined by three numeric notations. For example, the FG sandwich beam with 1-1-1 layer thickness ratio is the beam that has equal thickness for every layer. The heights in each layer of the beam are $h_{0}=-h / 2$, $h_{1}=-h / 6, h_{2}=+h / 6$ and $h_{3}=+h / 2$. The effective material properties in terms of Young's modulus of elasticity $(E)$ and mass density $(\rho)$ in each layer can be evaluated from the following equations:

$$
\begin{aligned}
& E^{(j)}(z)=\left(E_{b}-E_{t}\right) V_{b}^{(j)}(z)+E_{t}, \\
& \rho^{(j)}(z)=\left(\rho_{b}-\rho_{t}\right) V_{b}^{(j)}(z)+\rho_{t} .
\end{aligned}
$$

However, the Poisson's ratio ( $v)$ is assumed to be constant. From Eq. (1), it is noted that the superscript $(j)$ refers to layer and the subscripts $t$ and $b$ denote the material properties at the faces and at the core, respectively. The material volume fraction, $V_{b}^{(j)}$, which is based on the power law distribution can be obtained from Ref. [2,6] as:

$$
\begin{cases}V_{b}^{(1)}(z)=\left(\frac{z-h_{0}}{h_{1}-h_{0}}\right)^{n} & z \in\left[h_{0}, h_{1}\right] \\ V_{b}^{(2)}(z)=1 & z \in\left[h_{1}, h_{2}\right] \\ V_{b}^{(3)}(z)=\left(\frac{z-h_{3}}{h_{2}-h_{3}}\right)^{n} & z \in\left[h_{2}, h_{3}\right]\end{cases}
$$

where $n$ is the material volume fraction index or power law index, $0 \leq n \leq \infty$. For FG sandwich beam with homogenous hardcore, the core is made of ceramic phase $\left(E_{b}=E_{c}, \rho_{b}=\rho_{c}\right)$ and FG faces with top and bottom surfaces are made of metal phase $\left(E_{t}=E_{m}, \rho_{t}=\rho_{m}\right)$. In contrast, for FG sandwich beam with homogenous softcore, we have $\left(E_{b}=E_{m}, \rho_{b}=\rho_{m}\right)$ and $\left(E_{t}=E_{c}, \rho_{t}=\rho_{c}\right)$ where the subscripts $c$ and $m$ denote the material properties of ceramic and metal phases, respectively.

\section{Theoretical formulations}

Based on Timoshenko beam theory, the dynamic equation of motion governing FG sandwich beam behavior under dynamic loadings can be formulated by taking into account shear deformation effect. The displacements of an arbitrary point of the beams along the $x$ - and $z$-axes, which are denoted by $u(x, z)$, $w(x, z)$ respectively, can be expressed below:

$$
\begin{aligned}
& u(x, z, t)=u_{0}(x, t)+z \psi(x, t), \\
& w(x, z, t)=w_{0}(x, t),
\end{aligned}
$$

where $u_{0}$ are $w_{0}$ axial and transverse displacements in the middle plane $(z=0)$, respectively, $\psi$ is the rotation of the beam cross-section and $t$ is time. The strain-displacement relations in terms of normal strain $\left(\varepsilon_{x x}\right)$ and shear strain $\left(\gamma_{x z}\right)$ are given by;

$$
\varepsilon_{x x}=\frac{\partial u}{\partial x}=\frac{\partial u_{0}}{\partial x}+z \frac{\partial \psi}{\partial x}
$$


http://wjst.wu.ac.th

$$
\gamma_{x z}=\frac{\partial u}{\partial z}+\frac{\partial w}{\partial x}=\frac{\partial w_{0}}{\partial x}+\psi
$$

The corresponding normal stress $\left(\sigma_{x x}\right)$ and shear stress $\left(\tau_{x z}\right)$ can be obtained from the elastic constitutive law as;

$$
\sigma_{x x}=E(z) \varepsilon_{x x}, \tau_{x z}=G(z) \gamma_{x z}=\frac{E(z)}{2(1+v)} \gamma_{x z} .
$$

The strain energy $\left(U_{S}\right)$ of the FG sandwich beams at any instant can be defined as;

$U_{S}=\frac{b}{2} \int_{0}^{L} \int_{-h / 2}^{h / 2}\left(\sigma_{x x} \varepsilon_{x x}+\tau_{x z} \gamma_{x z}\right) d z d x$

Substituting Eqs. (4) and (5) into Eq. (6), one can obtain another form of the strain energy equation as;

$$
U_{S}=\frac{1}{2} \int_{0}^{L}\left[A_{11}\left(\frac{\partial u_{0}}{\partial x}\right)^{2}+2 B_{11} \frac{\partial u_{0}}{\partial x} \frac{\partial \psi}{\partial x}+D_{11}\left(\frac{\partial \psi}{\partial x}\right)^{2}+A_{55}\left(\frac{\partial w_{0}}{\partial x}\right)^{2}+2 A_{55} \psi \frac{\partial w_{0}}{\partial x}+A_{55} \psi^{2}\right] d x
$$

It is denoted that $A_{11}, A_{55}$ and $B_{11}$ and $D_{11}$ appearing in Eq. (7) are the extensional, shear, coupling and bending stiffness components which can be obtained from;

$$
\left[A_{11}, B_{11}, D_{11}\right]=b \sum_{j=1}^{3} \int_{h_{j-1}}^{h_{j}} E^{(j)}\left[1, z, z^{2}\right] d z \text {, and } A_{55}=b \kappa \sum_{j=1}^{3} \int_{h_{j-1}}^{h_{j}} \frac{E^{(j)}}{2(1+v)} d z
$$

where $\kappa=5 / 6$ is shear correction factor for layer of homogenous material and $\kappa=\frac{5}{6-\left(v_{c} V_{c}+v_{m} V_{m}\right)}$ for layer of FG material in which $V_{m}=1-V_{c}$ It is defined here that $V_{c}$ and $V_{m}$ are the material volume fractions of ceramic and metal, respectively. Similarly, $v_{c}$ and $v_{m}$ are the Poisson's ratios of ceramic and metal.

To consider the effect of the Pasternak elastic foundation, the potential energy due to the foundation is expressed as follows:

$$
U_{F}=\frac{1}{2} \int_{0}^{L}\left(k_{w} w_{0}^{2}+k_{s}\left(\frac{\partial w_{0}}{\partial x}\right)^{2}\right) d x
$$

where $k_{w}$ and $k_{s}$ are the constants of Winkler and shear layer springs per unit width, respectively.

For the kinetic energy of the beams, it can be expressed as;

$$
\begin{aligned}
U_{K} & =\frac{b}{2} \int_{0}^{L} \int_{-h / 2}^{h / 2} \rho(z)\left[\left(\frac{\partial u}{\partial t}\right)^{2}+\left(\frac{\partial w}{\partial t}\right)^{2}\right] d z d x \\
& =\frac{1}{2} \int_{0}^{L}\left[I_{0}\left(\frac{\partial u_{0}}{\partial t}\right)^{2}+2 I_{1} \frac{\partial u_{0}}{\partial t} \frac{\partial \psi}{\partial t}+I_{2}\left(\frac{\partial \psi}{\partial t}\right)^{2}+I_{0}\left(\frac{\partial w_{0}}{\partial t}\right)^{2}\right] d x
\end{aligned}
$$


http://wjst.wu.ac.th

where $I_{0}, I_{1}$ and $I_{2}$ are the inertia components which can be obtained from the following equation;

$\left[I_{0}, I_{1}, I_{2}\right]=b \sum_{j=1}^{3} \int_{h_{j-1}}^{h_{j}} \rho^{(j)}\left[1, z, z^{2}\right] d z$.

In this investigation, the multi-moving loads induced vibration of FG sandwich beams are considered, hence, the work done $\left(U_{E X}\right)$ due to the external loads depends on the number of loads moving onto the beams. As a result, the expressions of the work done for different number of moving loads can be obtained below:

For the case of one load moving onto the beams:

$U_{E X}= \begin{cases}-P_{1}(t) w_{0}\left(x_{P 1}, t\right) & \text { if } 0 \leq t \leq t_{1}=\frac{L}{v_{p}} \\ 0 & \text { if } t_{1}<t\end{cases}$

For the case of two loads moving onto the beams:

$U_{E X}= \begin{cases}-P_{1}(t) w_{0}\left(x_{P 1}, t\right) & \text { if } 0 \leq t<t_{1}=\frac{d}{v_{p}} \\ -P_{1}(t) w_{0}\left(x_{P 1}, t\right)-P_{2}(t) w_{0}\left(x_{P 2}, t\right) & \text { if } t_{1} \leq t \leq t_{2}=\frac{L}{v_{p}} \\ -P_{2}(t) w_{0}\left(x_{P 2}, t\right) & \text { if } t_{2}<t \leq t_{1}+t_{2} \\ 0 & \text { if } t_{1}+t_{2}<t\end{cases}$

For the case of three loads moving onto the beams:

$U_{E X}=\left\{\begin{array}{lc}-P_{1}(t) w_{0}\left(x_{P 1}, t\right) & \text { if } 0 \leq t<t_{1}=\frac{d}{v_{p}} \\ -P_{1}(t) w_{0}\left(x_{P 1}, t\right)-P_{2}(t) w_{0}\left(x_{P 2}, t\right) & \text { if } t_{1} \leq t<t_{2}=\frac{2 d}{v_{p}} \\ -P_{1}(t) w_{0}\left(x_{P 1}, t\right)-P_{2}(t) w_{0}\left(x_{P 2}, t\right)-P_{3}(t) w_{0}\left(x_{P 3}, t\right) & \text { if } t_{2} \leq t \leq t_{3}=\frac{L}{v_{p}} \\ -P_{2}(t) w_{0}\left(x_{P 2}, t\right)-P_{3}(t) w_{0}\left(x_{P 3}, t\right) & \text { if } t_{3}<t \leq t_{3}+t_{1} \\ -P_{3}(t) w_{0}\left(x_{P 3}, t\right) & \text { if } t_{3}+t_{1}<t \leq t_{3}+t_{2} \\ 0 & \text { if } t_{3}+t_{2}<t\end{array}\right.$

where

$P_{1}(t)=P_{0} \sin \left(\Omega_{1} t+\phi_{1}\right)$,

$P_{2}(t)=P_{0} \sin \left(\Omega_{2} t+\phi_{2}\right)$, 
http://wjst.wu.ac.th

$$
P_{3}(t)=P_{0} \sin \left(\Omega_{3} t+\phi_{3}\right) \text {. }
$$

It is defined that $P_{0}$ and $\Omega_{i}$ are the magnitude and excitation frequencies of the moving loads, respectively. $\phi_{i}$ are the phase angles of the moving loads.

Similarly, we can use the same principle, as shown in Eqs. (12) - (14), for the work done of the beams subjected to more than three moving loads or arbitrary number of moving loads.

From all energies described above, we can use them to create the total potential energy (П) for the beam system as follows:

$\Pi=U_{S}+U_{F}-U_{K}-U_{E X}$

To solve the total potential energy in Eq. (16), we can use the Ritz trial displacement functions in form of polynomial series that have to satisfy at least the essential or geometric boundary conditions. With different boundary conditions such as clamped $(\mathrm{C})$ and hinged $(\mathrm{H})$ at any end of the beams, the trial displacement functions are;

$$
\left\{\begin{array}{l}
u_{0}(x, t)=\sum_{j=1}^{N} A_{j}(t) \xi_{1 j}(x) \\
w_{0}(x, t)=\sum_{j=1}^{N} B_{j}(t) \xi_{2 j}(x) \\
\psi(x, t)=\sum_{j=1}^{N} C_{j}(t) \xi_{3 j}(x)
\end{array}\right.
$$

in which $\xi_{1 j}(x), \xi_{2 j}(x)$ and $\xi_{3 j}(x)$ are polynomial-series shape functions that are dependent on essential boundary conditions of the beams. The shape functions of the beams with different boundary conditions (B.C.) are shown in Table 1. For example, the beams which are hinged at both ends are defined as $\mathrm{H}-\mathrm{H}$ beams.

Table 1 Shape functions of FG sandwich beams with different boundary conditions.

\begin{tabular}{llll}
\hline B.C. & $\xi_{1 j}(x)$ & $\xi_{2 j}(x)$ & $\xi_{3 j}(x)$ \\
\hline C-C & $\left(\frac{x}{L}\right)^{j}\left(1-\frac{x}{L}\right)$ & $\left(\frac{x}{L}\right)^{j}\left(1-\frac{x}{L}\right)$ & $\left(\frac{x}{L}\right)^{j}\left(1-\frac{x}{L}\right)$ \\
C-H & $\left(\frac{x}{L}\right)^{j}\left(1-\frac{x}{L}\right)$ & $\left(\frac{x}{L}\right)^{j}\left(1-\frac{x}{L}\right)$ & $\left(\frac{x}{L}\right)^{j}$ \\
H-H & $\left(\frac{x}{L}\right)^{j}\left(1-\frac{x}{L}\right)$ & $\left(\frac{x}{L}\right)^{j}\left(1-\frac{x}{L}\right)$ & $\left(\frac{x}{L}\right)^{j-1}$
\end{tabular}

These shape functions are expanded to suitable number of polynomial terms $(N)$ which can find from convergence study. Inserting the trial displacement functions written above into the total potential energy of Eq. (16) and then following the Lagrange equation method; 
http://wjst.wu.ac.th

$$
\frac{\partial \Pi}{\partial q_{j}}-\frac{d}{d t} \frac{\partial \Pi}{\partial \dot{q}_{j}}=0
$$

with $q_{j}$ representing the time-dependent unknown parameters $\left(A_{j}(t), B_{j}(t), C_{j}(t)\right)$, one can obtain the following equation of motion;

$$
\left[\begin{array}{ccc}
K^{11} & K^{12} & K^{13} \\
\vdots & K^{22} & K^{23} \\
\operatorname{sym} & \cdots & K^{33}
\end{array}\right]\left[\begin{array}{l}
A \\
B \\
C
\end{array}\right]+\left[\begin{array}{ccc}
M^{11} & M^{12} & M^{13} \\
\vdots & M^{22} & M^{23} \\
\operatorname{sym} & \cdots & M^{33}
\end{array}\right]\left[\begin{array}{l}
\ddot{A} \\
\ddot{B} \\
\ddot{C}
\end{array}\right]=\left[\begin{array}{c}
0 \\
F \\
0
\end{array}\right] .
$$

It is noted that the over-dot stands for the derivative with respective to time, $\boldsymbol{K}$ and $\boldsymbol{M}$ are the stiffness and mass matrices, respectively, in which their size is $(3 N \times 3 N)$. Additionally, $\boldsymbol{F}$ is the vector of dynamic force due to the moving loads. The matrix elements in Eq. (19) are given by;

$$
\begin{aligned}
& K_{j m}^{11}=A_{11} \int_{0}^{L} \frac{\partial \xi_{1 j}}{\partial x} \frac{\partial \xi_{1 m}}{\partial x} d x, \quad K_{j m}^{12}=0, \quad K_{j m}^{13}=B_{11} \int_{0}^{L} \frac{\partial \xi_{1 j}}{\partial x} \frac{\partial \xi_{3 m}}{\partial x} d x, \\
& K_{j m}^{22}=\left(A_{55} \int_{0}^{L} \frac{\partial \xi_{2 j}}{\partial x} \frac{\partial \xi_{2 m}}{\partial x} d x+k_{w} \int_{0}^{L} \xi_{2 j} \xi_{2 m} d x+k_{s} \int_{0}^{L} \frac{\partial \xi_{2 j}}{\partial x} \frac{\partial \xi_{2 m}}{\partial x} d x\right) \\
& K_{j m}^{23}=A_{55} \int_{0}^{L} \frac{\partial \xi_{2 j}}{\partial x} \xi_{3 m} d x, K_{j m}^{33}=\left(D_{11} \int_{0}^{L} \frac{\partial \xi_{3 j}}{\partial x} \frac{\partial \xi_{3 m}}{\partial x} d x+A_{55} \int_{0}^{L} \xi_{3 j} \xi_{3 m} d x\right) \text {, } \\
& M_{j m}^{11}=I_{0} \int_{0}^{L} \xi_{1 j} \xi_{1 m} d x, \quad M_{j m}^{12}=0, \quad M_{j m}^{13}=I_{1} \int_{0}^{L} \xi_{1 j} \xi_{3 m} d x, \\
& M_{j m}^{22}=I_{0} \int_{0}^{L} \xi_{2 j} \xi_{2 m} d x, \quad M_{j m}^{23}=0, \quad M_{j m}^{33}=I_{2} \int_{0}^{L} \xi_{3 j} \xi_{3 m} d x, \\
& F_{j}=-P_{1}(t) \xi_{2 j}\left(x_{p 1}\right) \\
& \text { if } 0 \leq t<\frac{d}{v_{p}} \\
& F_{j}=-P_{1}(t) \xi_{2 j}\left(x_{p 1}\right)-P_{2}(t) \xi_{2 j}\left(x_{p 2}\right) \\
& \text { if } t_{1} \leq t<t_{2}=\frac{2 d}{v_{p}} \\
& F_{j}=-P_{1}(t) \xi_{2 j}\left(x_{p 1}\right)-P_{2}(t) \xi_{2 j}\left(x_{p 2}\right)-P_{3}(t) \xi_{2 j}\left(x_{p 3}\right) \\
& \text { if } t_{2} \leq t \leq t_{3}=\frac{L}{v_{p}} \\
& F_{j}=-P_{2}(t) \xi_{2 j}\left(x_{p 2}\right)-P_{3}(t) \xi_{2 j}\left(x_{p 3}\right) \\
& \text { if } t_{3}<t \leq t_{3}+t_{1} \\
& F_{j}=-P_{3}(t) \xi_{2 j}\left(x_{p 3}\right) \\
& \text { if } t_{3}+t_{1}<t \leq t_{3}+t_{2} \text {. }
\end{aligned}
$$

The equation of motion in Eq. (19) can be solved in time domain by using the average acceleration method of Newmark. Consequently, the results of displacements, velocities and accelerations of the beams at the considered point and time are determined in the time domain. For free vibration analysis with harmonic phenomenon, it is assumed that the unknown vector $\left[A_{j}(t), B_{j}(t), C_{j}(t)\right]^{T}$, for $j=1,2, \ldots N$ are expressed as; 


$$
\left[\begin{array}{l}
A_{j}(t) \\
B_{j}(t) \\
C_{j}(t)
\end{array}\right]=\left[\begin{array}{l}
\bar{A}_{j} e^{i \omega t} \\
\bar{B}_{j} e^{i \omega t} \\
\bar{C}_{j} e^{i \omega t}
\end{array}\right]
$$

in which $i=\sqrt{-1}$ and $\omega$ is natural frequency. Substituting Eq. (21) into Eq. (19) without considering any force vector, we can obtain an eigenvalue equation for free vibration problem as;

$$
\left[\left[\begin{array}{ccc}
K^{11} & K^{12} & K^{13} \\
\vdots & K^{22} & K^{23} \\
\operatorname{sym} & \cdots & K^{33}
\end{array}\right]-\omega^{2}\left[\begin{array}{ccc}
M^{11} & M^{12} & M^{13} \\
\vdots & M^{22} & M^{23} \\
\operatorname{sym} & \cdots & M^{33}
\end{array}\right]\right]\left[\begin{array}{c}
\bar{A} \\
\bar{B} \\
\bar{C}
\end{array}\right]=\left[\begin{array}{l}
0 \\
0 \\
0
\end{array}\right] .
$$

Solving Eq. (22) as standard eigenvalue problem leads to a set of natural frequencies of FG sandwich beams in which the lowest eigenvalue is the fundamental frequency of the beams.

\section{Results and discussions}

This section is given to present and discuss several examples of free and forced vibration analysis of FG sandwich beams made from a mixture of Alumina $\left(\mathrm{Al}_{2} \mathrm{O}_{3}\right)$ as ceramic phases and Aluminum $(\mathrm{Al})$ as metal phases. The material properties such as Young's modulus $(E)$, Poisson's ratio $(v)$ and material density $(\rho)$ are:

$E_{c}=380 \mathrm{GPa}, v_{c}=0.3, \rho_{c}=3960 \mathrm{~kg} / \mathrm{m}^{3}$ for $\mathrm{Al}_{2} \mathrm{O}_{3}$ and $E_{m}=70 \mathrm{GPa}, v_{m}=0.3, \rho_{m}=2702 \mathrm{~kg} / \mathrm{m}^{3}$ for Al

In this study, the geometric parameters of FG sandwich beams are as follows: $b=0.5 \mathrm{~m}, h=1.0 \mathrm{~m}$. This section is organized into two parts: free vibration analysis and forced vibration analysis with arbitrary number of loads moving onto the beams. In case of free vibration, the natural frequencies of the beams are presented in dimensionless form of $\tilde{\omega}=\frac{\omega L^{2}}{h} \sqrt{\frac{\rho_{m}}{E_{m}}}$.

Free vibration of FG sandwich beams

It is important to begin the vibration analysis of FG sandwich beams using the Ritz method with convergence study and validation that can be seen in Table 2. The beams having 1-1-1 layer thickness ratio and homogenous hardcore are chosen to be examined in this table. As can be observed, the accuracy of the first three modes of frequencies is improved as the increase of polynomial terms $(N)$. Using $N=10$ is enough to obtain the convergent results; hence, $N=10$ is used throughout this paper. The obtained frequency results of FG sandwich beams supported by different boundary conditions are in good agreement with the existing results in the literature $[2,6]$. 
http://wjst.wu.ac.th

Table 2 Convergence study and validation for free vibration of FG sandwich beams with different boundary conditions $(L / h=20)$.

\begin{tabular}{|c|c|c|c|c|c|c|c|}
\hline \multirow[b]{2}{*}{ B.C. } & \multirow[b]{2}{*}{$N$} & \multicolumn{3}{|l|}{$n=0.5$} & \multicolumn{3}{|l|}{$n=5.0$} \\
\hline & & $\tilde{\omega}_{1}$ & $\tilde{\omega}_{2}$ & $\tilde{\omega}_{3}$ & $\tilde{\omega}_{1}$ & $\tilde{\omega}_{2}$ & $\tilde{\omega}_{3}$ \\
\hline \multirow[t]{7}{*}{ H-H } & 4 & 4.5333 & 22.6918 & 57.8540 & 3.1111 & 15.6477 & 40.2473 \\
\hline & 6 & 4.5320 & 18.0237 & 40.3973 & 3.1102 & 12.4038 & 27.9275 \\
\hline & 8 & 4.5320 & 17.9495 & 39.7571 & 3.1102 & 12.3524 & 27.4790 \\
\hline & 9 & 4.5320 & 17.9492 & 39.7571 & 3.1102 & 12.3522 & 27.4790 \\
\hline & 10 & 4.5320 & 17.9492 & 39.7571 & 3.1102 & 12.3522 & 27.4790 \\
\hline & [2] & 4.5324 & - & - & 3.1111 & - & - \\
\hline & [6] & 4.5316 & 17.9436 & 39.7226 & 3.1101 & 12.3507 & 27.4651 \\
\hline \multirow[t]{5}{*}{ C-C } & 4 & 10.2026 & 28.0958 & 113.4970 & 7.0278 & 19.4596 & 98.5357 \\
\hline & 6 & 10.1734 & 27.5784 & 55.0180 & 7.0064 & 19.0917 & 38.4976 \\
\hline & 8 & 10.1733 & 27.5702 & 52.9340 & 7.0063 & 19.0858 & 36.8825 \\
\hline & 9 & 10.1733 & 27.5702 & 52.8762 & 7.0063 & 19.0858 & 36.8346 \\
\hline & 10 & 10.1733 & 27.5702 & 52.8759 & 7.0063 & 19.0858 & 36.8344 \\
\hline \multirow[t]{5}{*}{ C-H } & 4 & 7.0556 & 22.8653 & 77.0377 & 4.8497 & 15.7833 & 54.1573 \\
\hline & 6 & 7.0489 & 22.5459 & 47.3422 & 4.8450 & 15.5582 & 32.8640 \\
\hline & 8 & 7.0489 & 22.5401 & 46.1677 & 4.8450 & 15.5541 & 32.0305 \\
\hline & 9 & 7.0489 & 22.5401 & 46.1417 & 4.8450 & 15.5541 & 32.0119 \\
\hline & 10 & 7.0489 & 22.5401 & 46.1413 & 4.8450 & 15.5541 & 32.0116 \\
\hline
\end{tabular}

The present mathematical model is used further for the next investigations in our study. Table 3 tabulates the dimensionless frequency results of FG sandwich beams with symmetric (1-0-1, 1-1-1, 2-1-2) and asymmetric (2-2-1, 2-1-1, 3-2-1) layer thickness ratios for both homogenous hard and soft cores. The beams are clamped at both ends and the values of length to height ratio $(L / h)$ and the material volume fraction index $(n)$ are varied. Increasing the value of $n$ leads to the reduction in frequency of the beams with homogenous hardcore, while, it is not for the beams with homogenous softcore. This phenomenon is for beams with every $L / h$ ratio and pattern of layer thickness ratio.

Table 3 Dimensionless fundamental frequency ( $\tilde{\omega})$ of FG sandwich beams without elastic foundation.

\begin{tabular}{|c|c|c|c|c|c|c|c|}
\hline \multicolumn{8}{|c|}{ FG sandwich beams with homogenous hardcore } \\
\hline$L / h$ & $n$ & $1-0-1$ & $1-1-1$ & $2-1-2$ & $2-2-1$ & $2-1-1$ & $3-2-1$ \\
\hline \multirow[t]{4}{*}{5} & 0 & 10.0813 & 10.0541 & 10.0651 & 10.0486 & 10.0610 & 10.0541 \\
\hline & 0.5 & 8.2804 & 8.6518 & 8.4814 & 8.7814 & 8.5860 & 8.7362 \\
\hline & 1 & 7.2660 & 7.8504 & 7.5764 & 8.0572 & 7.7413 & 7.9783 \\
\hline & 2 & 6.2937 & 7.0193 & 6.6598 & 7.3029 & 6.8828 & 7.1997 \\
\hline \multirow[t]{3}{*}{10} & 0 & 11.6847 & 11.6741 & 11.6784 & 11.6719 & 11.6768 & 11.6741 \\
\hline & 0.5 & 9.3454 & 9.8006 & 9.5864 & 9.9725 & 9.7248 & 9.9223 \\
\hline & 1 & 8.0920 & 8.7723 & 8.4429 & 9.0357 & 8.6517 & 8.9504 \\
\hline
\end{tabular}


http://wjst.wu.ac.th

$\begin{array}{llllllll} & 2 & 6.9456 & 7.7409 & 7.3271 & 8.0895 & 7.5990 & 7.9834 \\ 20 & 0 & 12.2296 & 12.2266 & 12.2278 & 12.2260 & 12.2274 & 12.2266 \\ & 0.5 & 9.6884 & 10.1733 & 9.9433 & 10.3608 & 10.0941 & 10.3092 \\ & 1 & 8.3512 & 9.0634 & 8.7150 & 9.3469 & 8.9393 & 9.2598 \\ & 2 & 7.1467 & 7.9629 & 7.5315 & 8.3337 & 7.8200 & 8.2273\end{array}$

FG sandwich beams with homogenous softcore

\begin{tabular}{llllllll}
\hline 5 & 0 & 5.2382 & 5.2240 & 5.2297 & 5.2212 & 5.2276 & 5.2240 \\
& 0.5 & 8.4906 & 7.9529 & 8.2025 & 7.7094 & 8.0071 & 7.7134 \\
& 1 & 9.3002 & 8.7496 & 9.0172 & 8.4531 & 8.7838 & 8.4257 \\
& 2 & 9.8082 & 9.3350 & 9.5827 & 9.0126 & 9.3360 & 8.9475 \\
10 & 0 & 6.0713 & 6.0658 & 6.0680 & 6.0646 & 6.0672 & 6.0658 \\
& 0.5 & 10.2146 & 9.6791 & 9.9430 & 9.3451 & 9.6664 & 9.2669 \\
& 1 & 11.1579 & 10.6832 & 10.9382 & 10.2777 & 10.6088 & 10.1228 \\
& 2 & 11.6755 & 11.3754 & 11.5716 & 10.9412 & 11.2296 & 10.7097 \\
20 & 0 & 6.3544 & 6.3528 & 6.3535 & 6.3525 & 6.3532 & 6.3528 \\
& 0.5 & 10.8471 & 10.3277 & 10.5916 & 9.9548 & 10.2797 & 9.8356 \\
& 1 & 11.8358 & 11.4149 & 11.6554 & 10.9624 & 11.2842 & 10.7443 \\
& 2 & 12.3460 & 12.1446 & 12.3072 & 11.6627 & 11.9245 & 11.3502 \\
& & & & & & & \\
\hline
\end{tabular}

The free vibration results in Tables $\mathbf{1}$ and $\mathbf{2}$ are natural frequencies of FG sandwich beams without elastic foundation. Therefore, in Table 4, we consider the effect of elastic foundation on fundamental frequency of the beams with different values of spring constants at the foundation. To be consistent with Ref. [6] for validation in this table, the dimensionless fundamental frequency is present in the form of $\bar{\omega}=\omega L \sqrt{\rho_{m} / E_{m}}$. The spring constants are obtained from $k_{w}=\xi_{w} A_{110} / L^{2}$ and $k_{s}=\xi_{s} A_{110}$ in which $A_{110}=E_{m} h$. It is defined that $A_{110}$ is $A_{11}$ of pure Aluminum beam per unit width. It is observed that the Ritz solutions of this present study are in excellent agreement with the previous results obtained from Chebyshev collocation method of Ref. [6] for the beams with and without elastic foundation. Therefore, our modeling based on the Ritz method is confirmed to be correct and it can be used to deal with free and forced vibration of the beams.

Table 4 Dimensionless fundamental frequency $(\bar{\omega})$ of FG sandwich beams with elastic foundation $(L / h=$ $10, n=0.5)$.

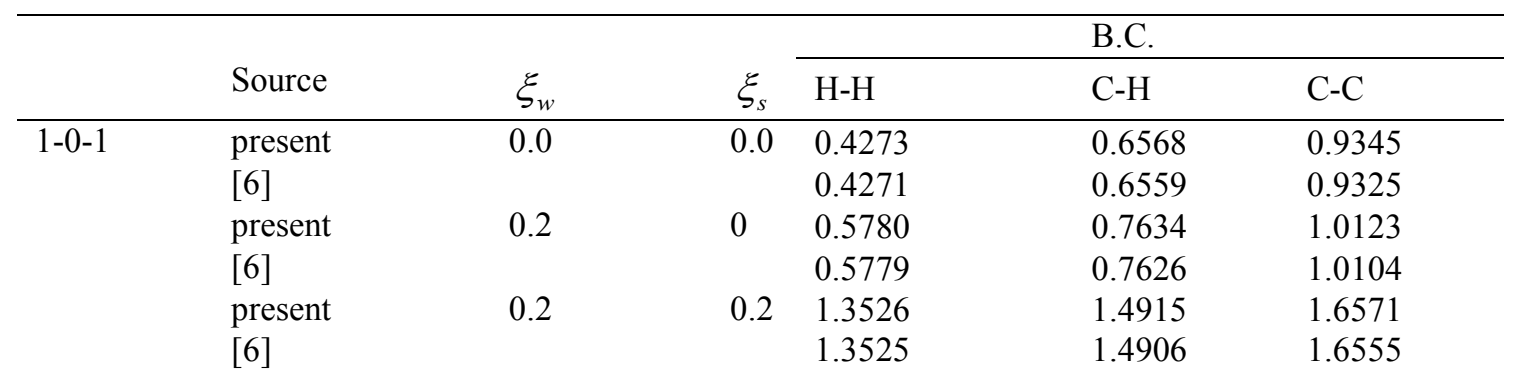




\begin{tabular}{lllllll}
\hline & & & & & B.C. & \\
\cline { 4 - 6 } & Source & $\xi_{w}$ & $\xi_{s}$ & H-H & C-H & C-C \\
\hline $1-1-1$ & present & 0.0 & 0.0 & 0.4487 & 0.6893 & 0.9801 \\
& {$[6]$} & & & 0.4486 & 0.6887 & 0.9787 \\
& present & 0.2 & 0 & 0.5892 & 0.7879 & 1.0518 \\
& {$[6]$} & & & 0.5891 & 0.7874 & 1.0505 \\
& present & 0.2 & 0.2 & 1.3363 & 1.4849 & 1.6635 \\
& {$[6]$} & & & 1.3363 & 1.4844 & 1.6622 \\
& present & 0.0 & 0.0 & 0.4386 & 0.6739 & 0.9586 \\
& {$[6]$} & & & 0.4384 & 0.6732 & 0.9570 \\
& present & 0.2 & 0 & 0.5834 & 0.7759 & 1.0329 \\
& {$[6]$} & & & 0.5833 & 0.7753 & 1.0314 \\
& present & 0.2 & 0.2 & 1.3421 & 1.4862 & 1.6588 \\
& {$[6]$} & & & 1.3420 & 1.4855 & 1.6572 \\
& present & 0.0 & 0.0 & 0.4921 & 0.7542 & 1.0696 \\
& {$[6]$} & & & 0.4920 & 0.7539 & 1.0690 \\
& present & 0.2 & 0 & 0.6179 & 0.8416 & 1.1330 \\
& {$[6]$} & & & 0.6178 & 0.8414 & 1.1324 \\
& present & 0.2 & 0.2 & 1.3268 & 1.4939 & 1.6968 \\
& {$[6]$} & & & 1.3267 & 1.4937 & 1.6962 \\
\hline
\end{tabular}

Forced vibration of FG sandwich beams under arbitrary number of moving loads

Similarly, this section also starts with numerical validation for forced vibration of beams. Here, we adopt the analytical model [27] used for predicting dynamic deflection of simply supported or hinged isotropic beams under a moving load. The model of Ref. [27] is

$$
w(x, t)=\sum_{i=1}^{\Delta} \frac{2 P_{0}}{\rho b h L} \frac{1}{\left(i \pi v_{p} / L\right)^{2}-\omega_{i}^{2}}\left(\sin \left(\frac{i \pi v_{p}}{L}\right) t-\frac{i \pi v_{p}}{L \omega_{i}} \sin \left(\omega_{i} t\right)\right) \sin \left(\frac{i \pi x}{L}\right)
$$

Where $\left(0 \leq t \leq \frac{L}{v_{p}}\right)$ and $\omega_{i}=\left(\frac{i \pi}{L}\right)^{2} \sqrt{\frac{E h^{2}}{12 \rho}} \quad i=1,2, \ldots . \Delta$.

We use the model in Eq. (23) for validating the present solution of the beam made of Aluminum 2024-T3 which has $E=72.4 \mathrm{GPa}$ and $\rho=2770 \mathrm{~kg} / \mathrm{m}^{3}$ As illustrated in Figure 2, This validation shows very good agreement between the present and analytical solutions. 
http://wjst.wu.ac.th

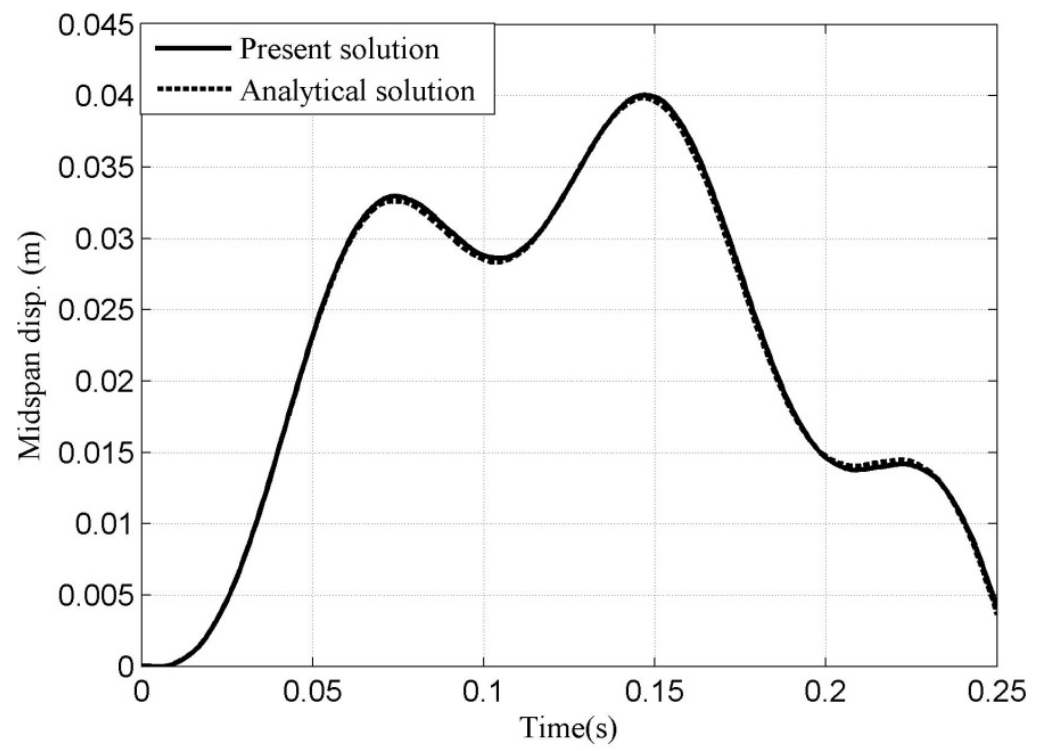

Figure 2 Comparison of the mid-span deflections of isotropic beams $L=10 \mathrm{~m}, b=0.4 \mathrm{~m}, h=0.5 \mathrm{~m}, v_{p}=$ $40 \mathrm{~m} / \mathrm{s}, P_{0}=500 \mathrm{kN}$.

However, the analytical model of Eq. (23) can be used to predict dynamic response of isotropic beams under only one moving load. Therefore, to extend research work, the present model of this paper can be applied to investigate the dynamic behavior of FG sandwich beams subjected to arbitrary number of loads moving on the beams. The significant parametric studies such as velocity, phase angle and excitation frequency of the loads, layer thickness ratio, boundary condition, length to height or beam thickness ratio as well as spring constants at the foundation, which have considerable impact on dynamic response of the beams, are taken into consideration. In order to make the results universal, the dimensionless form of dynamic deflection is presented by normalizing with the static deflection ( $\left.w_{s}=P_{0} L^{3} / 48 E I\right)$ of fully Aluminum beam under one point load $P_{0}$ at the mid-span of the beam. The magnitude of the moving and static load $\left(P_{0}\right)$ is set as $P_{0}=500 \mathrm{kN}$ throughout this paper. However, the dimensionless or normalized deflections may not depend on the magnitude of the moving loads.

In what follows, the dynamic behavior of FG sandwich beams without elastic foundation which are subjected to a number of moving loads is investigated in Figures 3 - 6. As can be seen in Figure 3, the maximum dimensionless dynamic deflection $\left(w(x, t) / w_{s}\right)$ of the 2-1-2 beams with homogenous hardcore is illustrated using H-H boundary condition. It is assumed that the first load starts to come onto the beam at the left end $(t=0)$ and the second one is at the left end of the beam when $\left(t=d / v_{p}\right)$. For the loads leave the beam, when $t>L / v_{p}$, the first load leaves the beam and when $\left(t>(L+d) / v_{p}\right)$ is the time for the second load leaves the beam. As can be seen, increasing the number of loads leads to dramatic increase of dynamic deflection. The maximum deflection appears in the graphic line of five loads moving onto the beam. 


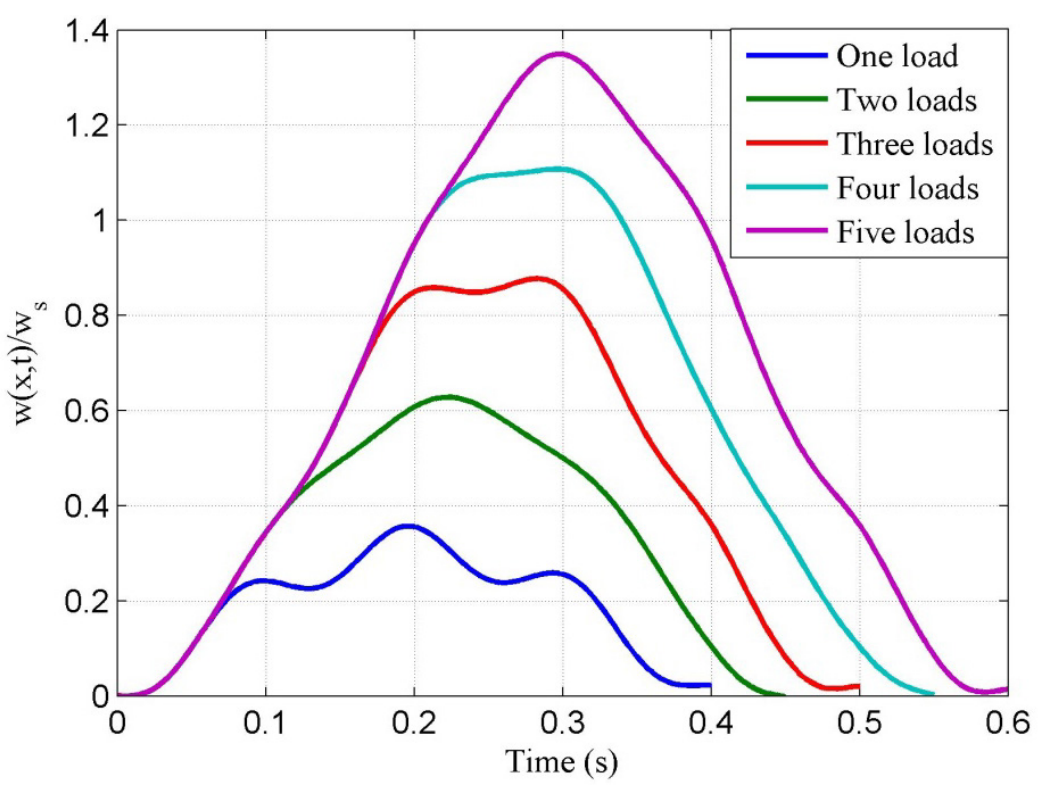

Figure 3 Maximum dimensionless dynamic deflections at the centre of FG sandwich beams under different number of moving loads $\left(L / h=20, n=0.5, d=L / 8, v_{p}=50 \mathrm{~m} / \mathrm{s}, \Omega_{i}=0\right)$.

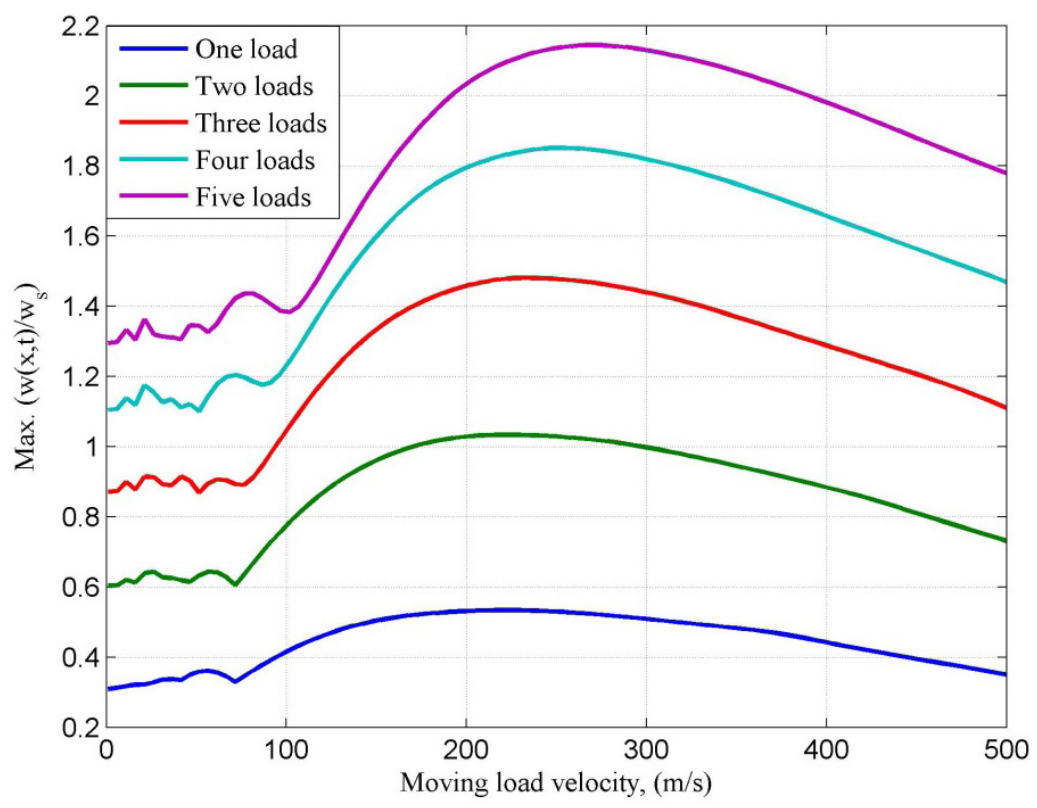

Figure 4 Maximum dimensionless dynamic deflections at the centre of FG sandwich beams under different number of moving loads $\left(L / h=20, n=0.5, d=L / 8, \Omega_{i}=0\right)$. 
http://wjst.wu.ac.th

Figure 4 plots the dynamic deflection versus the velocity $\left(v_{p}\right)$ of the loads for FG sandwich beams (2-1-2) with homogenous hardcore and hinged boundary condition at both ends. The trend of the deflection changes due to an increase of the velocity is similar for all beams subjected to different number of loads. That is the maximum deflection initially increases with fluctuations and then increases dramatically to reach the peak value before dropping down after the peak. The velocity at the peak is known as the critical velocity.

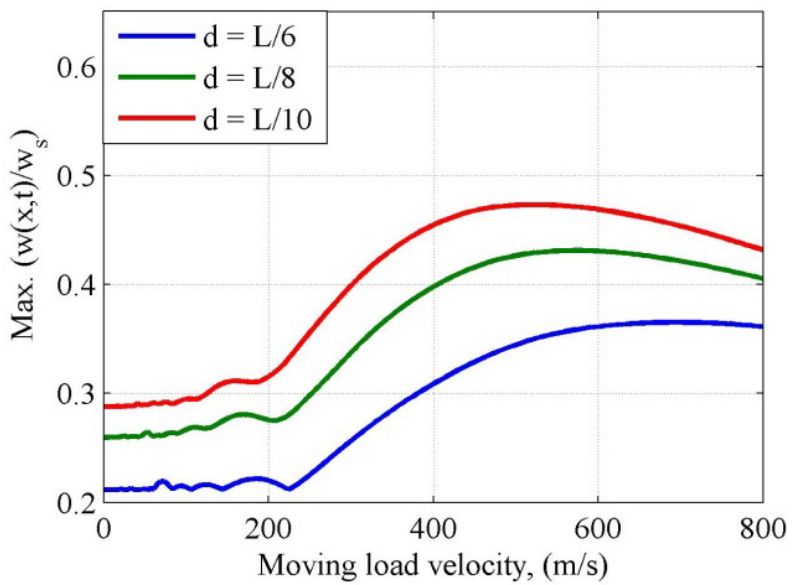

(a) homogenous hardcore

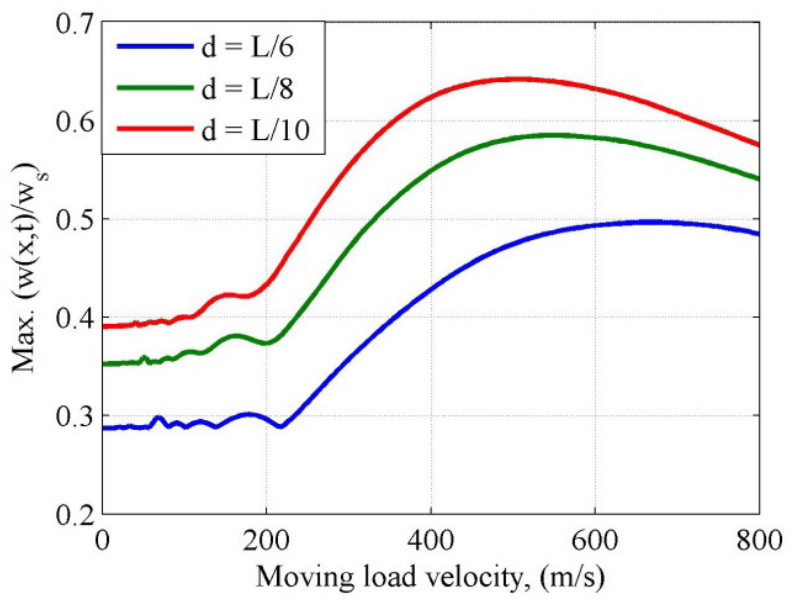

(b) homogenous softcore

Figure 5 Maximum dimensionless dynamic deflections at the centre of FG sandwich beams under five moving loads $\left(L / h=20, n=0.5, \Omega_{i}=0\right)$.

In Figure 5, the dynamic deflections of un-symmetric layer (2-2-1) beams are considered by varying value of velocity. The beams are clamped at both ends and subjected to five moving loads with different distances $(d)$. As can be observed, the loads with short distance $(d=L / 10)$ cause larger deflection of the beams than the loads having longer distances $(d=L / 8$ and $d=L / 6)$. Furthermore, in this figure, we can see that the beams with homogenous hardcore are much stronger (less deflections) than the beams with homogenous softcore. 
http://wjst.wu.ac.th

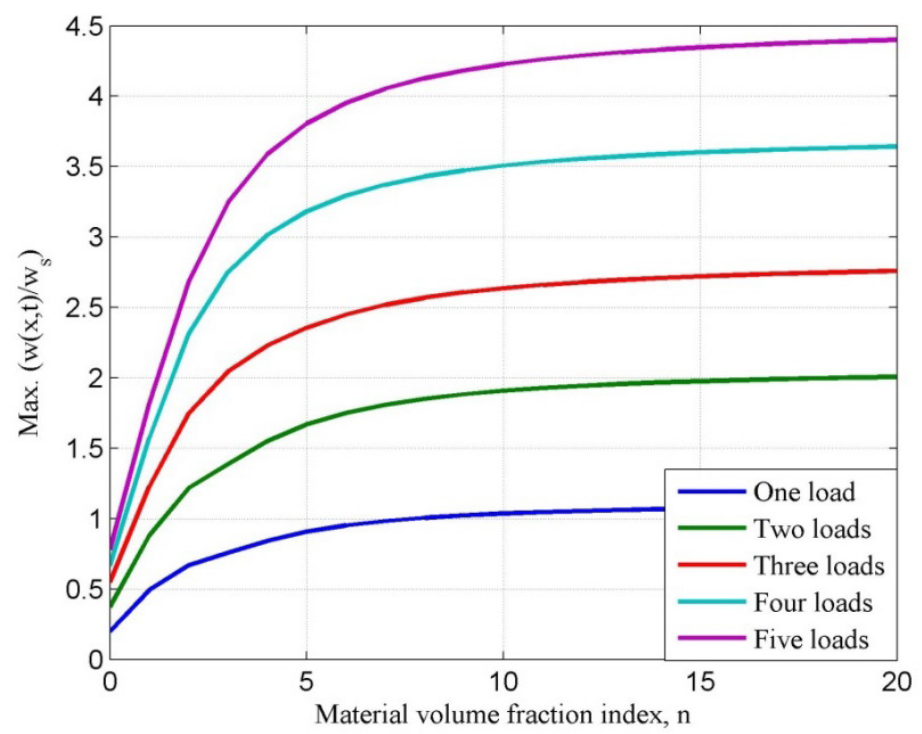

Figure 6 Effect of material volume fraction indexes $(n)$ on maximum dynamic deflections at the centre of FG sandwich beams $\left(L / h=20, d=L / 8, v_{p}=50 \mathrm{~m} / \mathrm{s}, \Omega_{i}=0\right)$.

To consider the effect of material volume fraction index $(n)$ on dynamic deflections, Figure 6 shows the plot of the deflections of FG sandwich beams against the values of the index $(n)$. In this figure, the symmetric layer (2-1-2) beams with homogenous hardcore are in the action of different number of moving loads and the beams are hinged at both ends. Based on this study, it is found that increasing value of $n$ yields the increase of the dynamic deflection. Therefore, it can be said that $n$ affects significantly the material stiffness components, especially flexural bending stiffness.

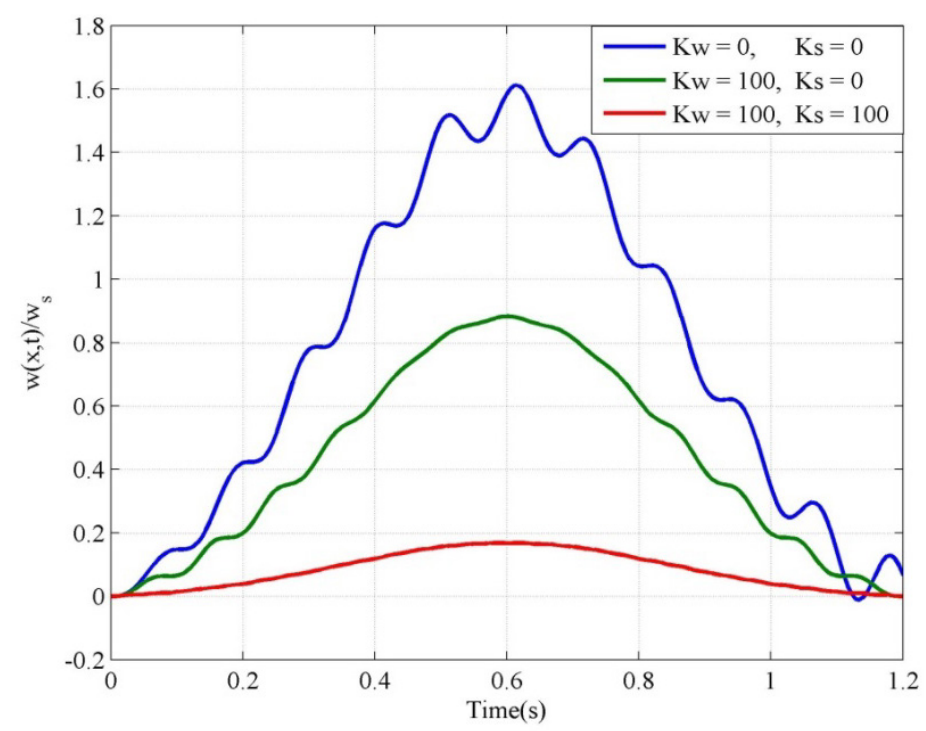

Figure 7 Effect of spring constants on maximum dimensionless dynamic deflections at the centre of FG sandwich beams under five moving loads $\left(L / h=20, n=0.5, d=L / 8, v_{p}=25 \mathrm{~m} / \mathrm{s}, \Omega_{i}=0\right)$. 
http://wjst.wu.ac.th

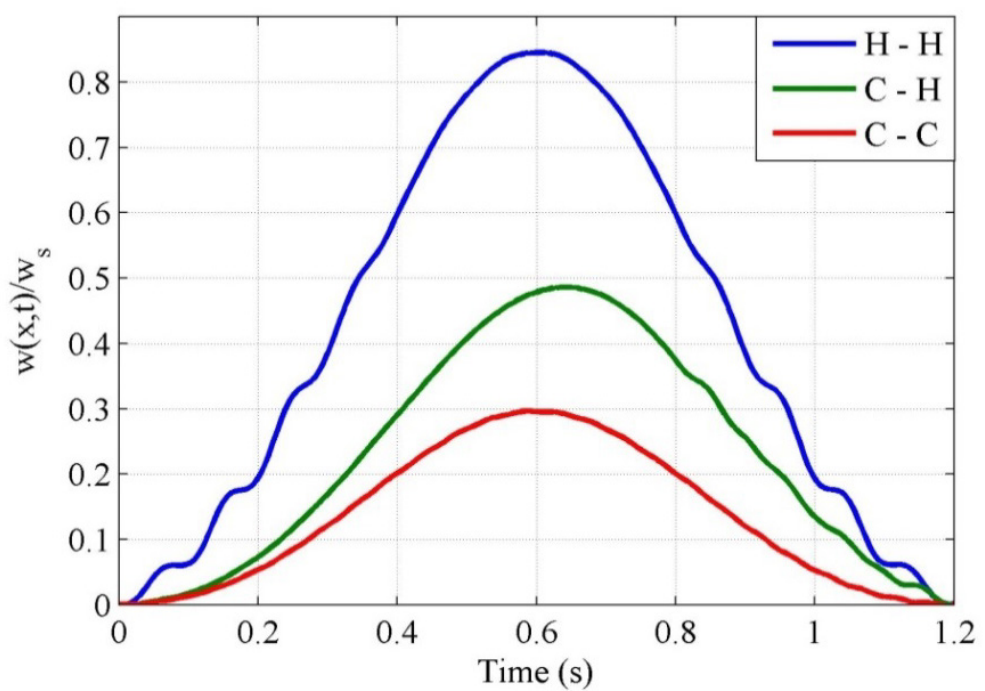

Figure 8 Effect of boundary conditions on maximum dimensionless dynamic deflections at the centre of FG sandwich beams under five moving loads $\left(L / h=20, n=0.5, d=L / 8, v_{p}=25 \mathrm{~m} / \mathrm{s}, K_{w}=10, K_{s}=10\right.$, $\left.\Omega_{i}=0\right)$.

Now, we move to the consideration of elastic foundation effect on dynamic behavior of FG sandwich beams under multiple moving loads. The spring constants in Eq. (9) can be calculated from $k_{w}=$ $K_{w} D_{110} / L^{4}$ and $k_{s}=K_{s} D_{110} / L^{2}$ where $D_{110}$ is $D_{11}$ of Aluminum beam per unit width. The 3-2-1 beam (homogenous softcore) which is hinged at both ends is considered in Figure 7 for analyzing the elastic foundation effect on the dynamic deflection. It is clearly seen that the deflection of the beam without elastic foundation $\left(K_{w}=0, K_{s}=0\right)$ is much higher than that of the beams with $\left(K_{w}=100, K_{s}=0\right)$ and $\left(K_{w}\right.$ $\left.=100, K_{s}=100\right)$, respectively. Therefore, it can be said that the elastic foundation plays a vital role in reducing dynamic deflection of FG sandwich beams, especially the Pasternak elastic foundation including shear layer spring stiffness.

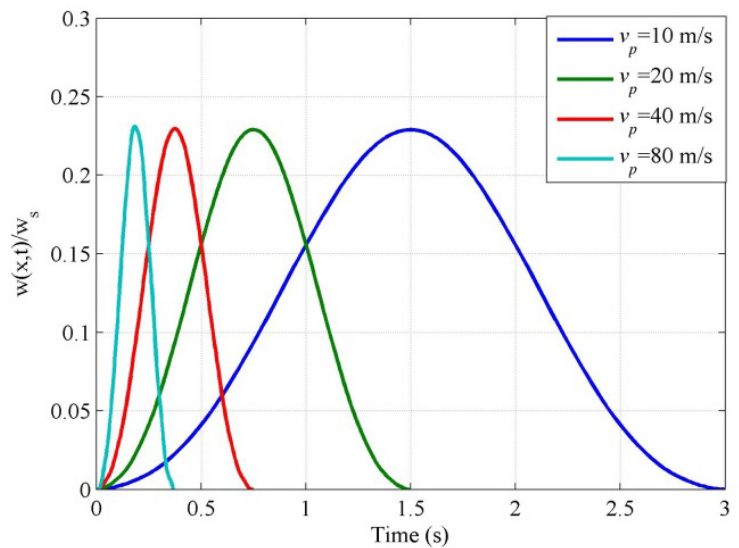

(a) homogenous hardcore

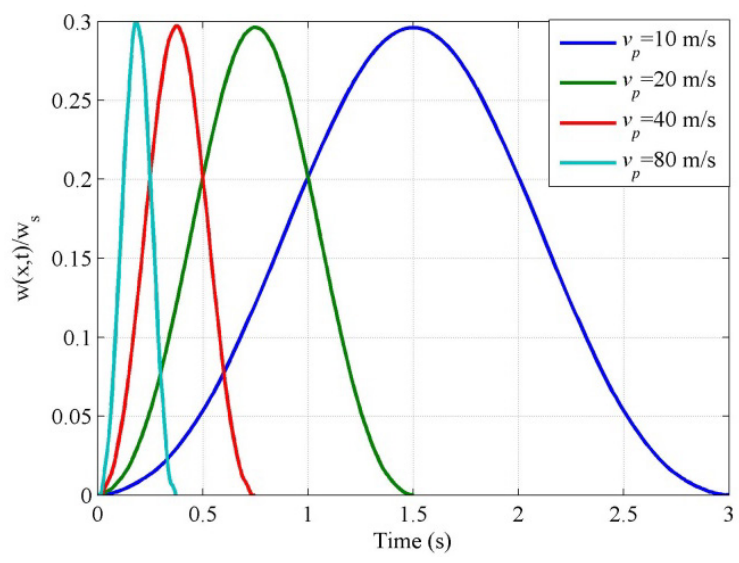

(b) homogenous softcore

Figure 9 Maximum dimensionless dynamic deflections at the centre of FG sandwich beams under five moving loads $\left(L / h=20, n=0.5, d=L / 8, K_{w}=10, K_{s}=10, \Omega_{i}=0\right)$. 
http://wjst.wu.ac.th

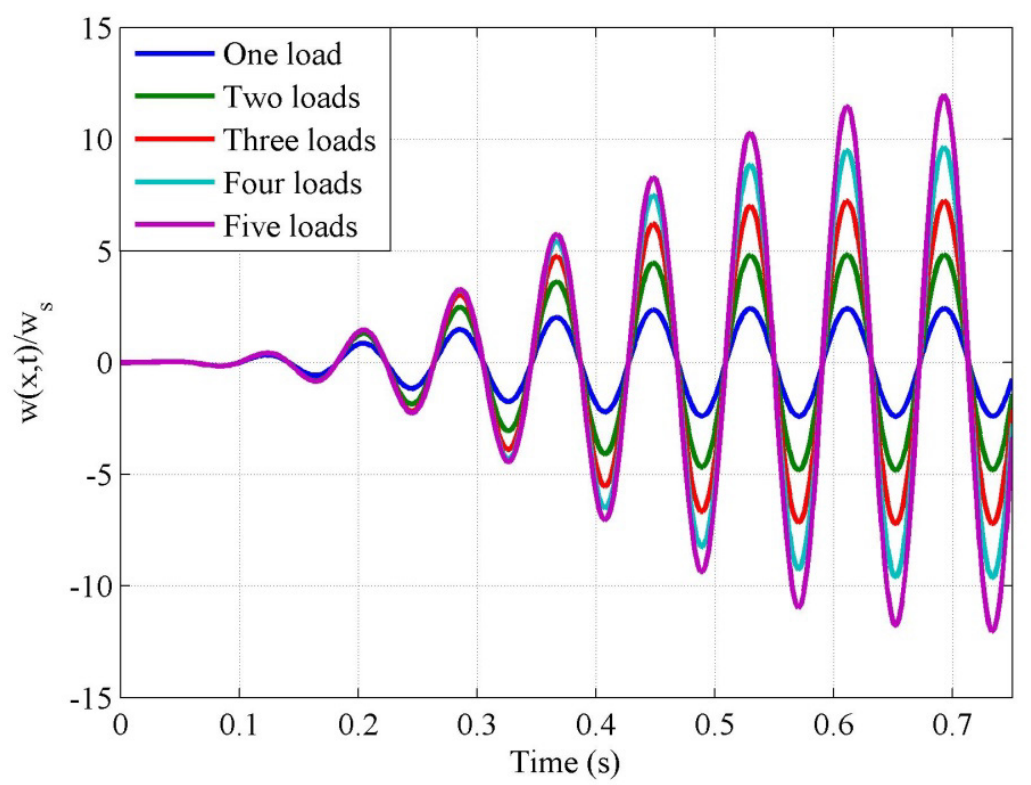

Figure 10 Maximum dimensionless dynamic deflections at the centre of FG sandwich beams under different number of moving loads $\left(L / h=20, n=0.5, d=L / 8, v_{p}=40 \mathrm{~m} / \mathrm{s} K_{w}=10, K_{s}=10, \Omega_{i}=\omega_{1}\right)$

In Figure 8, the dynamic deflections of 3-2-1 homogenous softcore beams subjected to five moving loads are presented with different boundary conditions. Of course, $\mathrm{C}-\mathrm{C}$ beam is a hard system which has less deflection than that of $\mathrm{C}-\mathrm{H}$ and $\mathrm{H}-\mathrm{H}$ beams, respectively. The explanation about this behavior is that the clamped condition has very high constrained; while, hinged condition is more relaxed and allows more movement at boundary condition. Furthermore, the effect of velocity of the moving loads is investigated in Figure 9 for the deflections of 3-2-1 beams supported by C-C boundary condition. The dynamic deflection of the homogenous hardcore beam, Figure 9(a), is lower than that of the homogenous softcore beam, Figure 9(b), for every value of velocity. The deflection is peak at the middle of travelling time of the loads.

The previous investigations presented above are considered without any frequency excitation of the moving loads $\left(\Omega_{i}=0\right)$. Hence, the next investigations will take into account the significant effect of the external excitation on dynamic behavior of FG sandwich beams resting on elastic foundation. The excitation frequency of every load is set in resonance in which the frequency of the loads is equivalent to the fundamental frequency of the beam. Next, the dynamic deflection of 2-2-1 homogenous softcore beams is analyzed in Figure 10 with different number of moving loads $\left(v_{p}=40 \mathrm{~m} / \mathrm{s}\right)$. The beams are placed on elastic foundation and hinged at both ends $(\mathrm{H}-\mathrm{H})$. In this figure, overall magnitude of five loads is very high that is the reason why the highest deflection is observed throughout the travelling time with the same speed. 


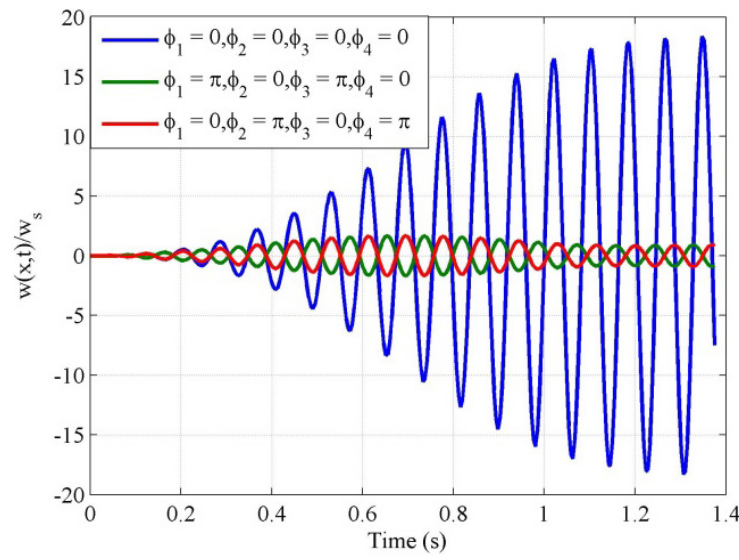

(a) $v_{p}=20 \mathrm{~m} / \mathrm{s}$

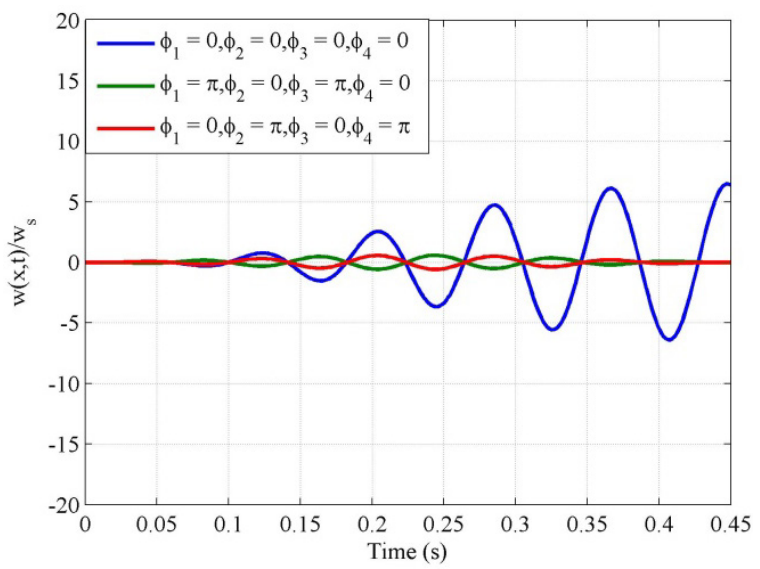

(c) $v_{p}=60 \mathrm{~m} / \mathrm{s}$

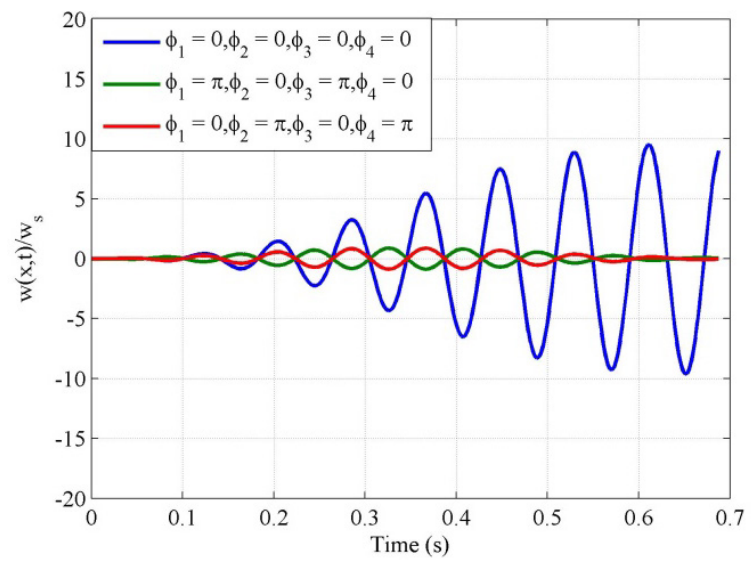

(b) $v_{p}=40 \mathrm{~m} / \mathrm{s}$

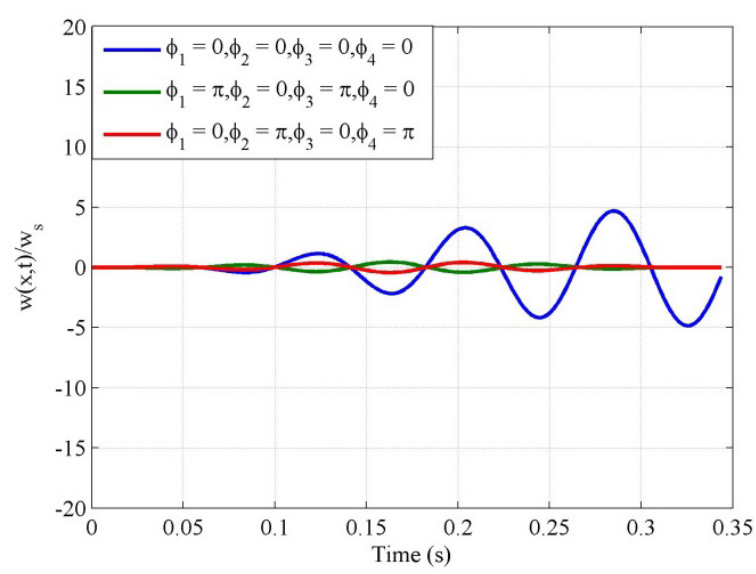

(d) $v_{p}=80 \mathrm{~m} / \mathrm{s}$

Figure 11 Effect of phase angles on maximum dimensionless dynamic deflections at the centre of FG sandwich beams under four moving loads $L / h=20, n=0.5, d=L / 8, K_{w}=10, K_{s}=10, \Omega_{i}=\omega_{1}$ )

The dynamic deflections of 2-2-1 homogenous softcore beams are solved and presented in Figures 11(a) - 11(d) using different velocities of four moving loads which are 20, 40, 60 and $80 \mathrm{~m} / \mathrm{s}$ for Figures 11(a) - 11(d), respectively. The beams are hinged at both ends. The results show that the phase angles can be used to reduce the dynamic deflections of the beams. As can be observed, the deflections of the beams without phase angles $\left(\phi_{1}=\phi_{2}=\phi_{3}=\phi_{4}=0\right)$ are higher than those of the beams with $\left(\phi_{1}=\pi, \phi_{2}=0, \phi_{3}=\right.$ $\left.\pi, \phi_{4}=0\right)$ and $\left(\phi_{1}=0, \phi_{2}=\pi, \phi_{3}=0, \phi_{4}=\pi\right)$.

Moreover, the following investigation is focused on the dynamic deflections of FG sandwich beams composed of different layer thickness ratios in Figure 12. The beams are homogenous softcore and they are supported by $\mathrm{H}-\mathrm{H}$ at the boundary condition. From this figure, it is found that the deflections are slightly different from each other throughout the travelling time. 


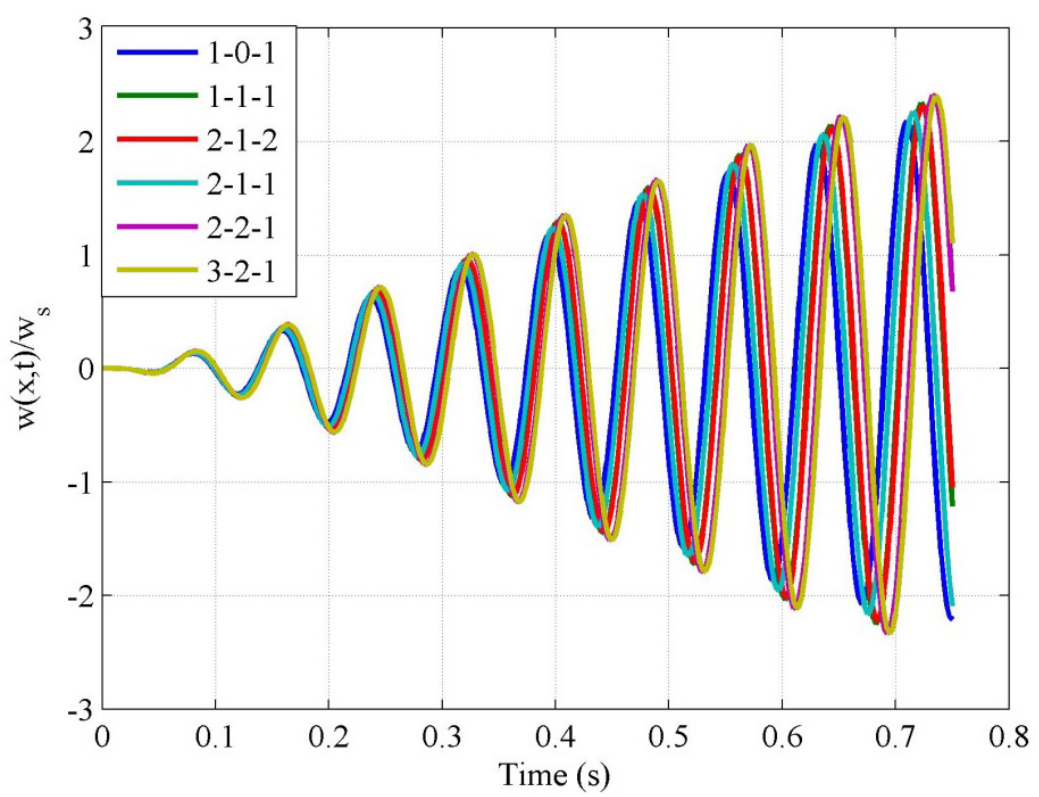

Figure 12 Effect of layer thickness ratios on maximum dimensionless dynamic deflections at the centre of FG sandwich beams under five moving loads $\left(L / h=20, n=0.5, d=L / 8, v_{p}=40 \mathrm{~m} / \mathrm{s}, K_{w}=10, K_{s}=10\right.$, $\left.\Omega_{i}=\omega_{1}\right)$

\section{Conclusions}

According to the literature survey, there are no solutions for FG sandwich beams' dynamic behavior resting on the Pasternak elastic foundation under the arbitrary number of harmonic moving loads. Therefore, this present study aims to investigate such a behavior of the beams using the Ritz method in conjunction with the time integration of Newmark. Using the Timoshenko beam theory, including the effects of shear deformation and rotary inertia, the motion equation is established for the beams with different boundary conditions. The influences of parametric studies such as layer thickness ratio, boundary condition, spring constants, length to height ratio, material volume fraction index of the beams, and excitation frequency and velocity phase angle of the loads on dynamic deflection results are presented and discussed.

In the section of free vibration analysis, it can be concluded that increasing the value of material volume fraction index $(n)$ leads to the reduction in the frequency of FG sandwich beams with homogenous hardcore, while it is not for the beams with homogenous softcore. The beams' frequency is increased as the increases of length to height ratio and spring constants for every layer thickness ratio. The beam's frequency with $\mathrm{C}-\mathrm{C}$ boundary conditions is higher than that of the beam with $\mathrm{C}-\mathrm{H}$ and $\mathrm{H}-\mathrm{H}$ boundary conditions, respectively.

For forced vibration of the beams subjected to the arbitrary number of harmonic moving loads, the new conclusions, which will be beneficial for structural design, can be revealed as follows:

- The dynamic deflection of the FG sandwich beam under moving loads increases initially with fluctuations and increases to the ultimate point at the critical velocity before dropping down after the point.

- The dynamic deflection of the FG sandwich beam subjected to the loads with short distance is larger than the beam subjected to the loads with long distance.

- FG sandwich beam with homogenous hardcore is stronger than the beam with homogenous softcore. 
http://wjst.wu.ac.th

- The dynamic deflection of the beam with homogenous hardcore is increased as the increase of value $n$, while it is reversed for the beam with homogenous softcore.

- The dynamic deflection of the beam, which is hinged at both ends $(\mathrm{H}-\mathrm{H})$, is much larger than that of the beams with $\mathrm{C}-\mathrm{H}$ and $\mathrm{C}-\mathrm{C}$ boundary conditions, respectively.

- For FG sandwich beams with homogenous hardcore, the largest deflection is found in the case of 1-0-1 beam, and the lowest one is for 2-2-1 beam.

- Increasing the spring constants at the elastic foundation yields a significant decrease in the dynamic deflection.

- The phase angles can be used to reduce the dynamic deflections of the beams.

\section{References}

[1] JR Vinson. The Behavior of Sandwich Structures of Isotropic and Composite Materials. Technomic Publication, Pennsylvania, USA, 1999.

[2] TP Vo, HT Thai, TK Nguyen, A Maheri and J Lee. Finite element model for vibration and buckling of functionally graded sandwich beams based on a refined shear deformation theory. Eng. Struc. 2014; 64, 12-22.

[3] TK Nguyen, TTP Nguyen, TP Vo and HT Thai. Vibration and buckling analysis of functionally graded sandwich beams by a new higher-order shear deformation theory. Compos. Part B 2015; 76, 273-85.

[4] TP Vo, HT Thai, TK Nguyen, F Inam and J Lee. A quasi-3D theory for vibration and buckling of functionally graded sandwich beams. Compos. Struc. 2015; 119, 1-12.

[5] TP Vo, HT Thai, TK Nguyen, F Inam and J Lee. Static behaviour of functionally graded sandwich beams using a quasi-3D theory. Compos. Part B 2015; 68, 59-74.

[6] P Tossapanon and $\mathrm{N}$ Wattanasakulpong. Stability and free vibration of functionally graded sandwich beams resting on two-parameter elastic foundation. Compos. Struc. 2016; 142, 215-25

[7] C L Trinh, TP Vo, AI Osofero and J Lee. Fundamental frequency analysis of functionally graded sandwich beams based on the state space approach. Compos. Struc. 2016; 156, 263-75.

[8] TQ Bui, A Khosravifard, Ch Zhang, MR Hematiyan and MV Golub. Dynamic analysis of sandwich beams with functionally graded core using a truly meshfree radial point interpolation method. Eng. Struc. 2013; 47, 90-104.

[9] AM Zenkour. A comprehensive analysis of functionally graded sandwich plates: Part 1-deflection and stresses. Int. J. Solids Struct. 2005; 42, 5224-42.

[10] AM Zenkour. A comprehensive analysis functionally graded sandwich plates: Part 2-Buckling and free vibration. Int. J. Solids Struct. 2005; 42, 5243-58.

[11] AMA Neves, AJM Ferreira, E Carrera, M Cinefra, RMN Jorge and CMM Soares. Static analysis of functionally graded sandwich plates according to a hyperbolic theory considering Zig-Zag and warping effects. Adv. Eng. Soft. 2012; 52, 30-43.

[12] Q Li, VP Iu and KP Kou. Three-dimensional vibration analysis of functionally graded material sandwich plates. J. Sound Vib. 2008; 311, 498-515.

[13] M Kashtalyan and M Menshykova. Three-dimensional elasticity solutions for sandwich panels with a functionally graded core. Compu. Struc. 2009; 87, 36-43.

[14] S Natarajan and G Manickam. Bending and vibration of functionally graded material sandwich plates using an accurate theory. Fin. Ele. Ana. Des. 2012; 57, 32-42.

[15] O Rahmani, SMR Khalili, K Malekzadeh and H Hadavinia. Free vibration analysis of sandwich structures with a flexible functionally graded syntactic core. Compu. Struc. 2009; 91, 229-35.

[16] M Liu, Y Cheng and J Liu. High-order free vibration analysis of sandwich plates with both functionally graded face sheets and functionally graded flexible core. Compos. Part B 2015; 72, 97107.

[17] AH Sofiyev. The vibration and buckling of sandwich cylindrical shells covered by different coating subjected to the hydrostatic pressure. Compos. Struc. 2014; 117, 124-34. 
http://wjst.wu.ac.th

[18] AH Sofiyev. Influences of shear stresses on the dynamic instability of exponentially graded sandwich cylindrical shells. Compos. Part B 2015; 77, 349-62.

[19] M Şimşek and T Kocatürk. Free and forced vibration of a functionally graded beam subjected to a concentrated moving load. Compos. Struc. 2009; 90, 465-73.

[20] M Şimşek. Non-linear vibration analysis of a functionally graded Timoshenko beam under action of a moving harmonic load. Compos. Struc. 2010; 92, 2532-46.

[21] M Şimşek, T Kocatürk and ŞD Akbaş. Dynamic behavior of an axially functionally graded beam under action of a moving harmonic load. Compos. Struc. 2012; 94, 2358-64.

[22] M Şimşek. Bi-directional functionally graded materials (BDFGMs) for free and forced vibration of Timoshenko beams with various boundary conditions. Compos. Struc. 2015; 133, 968-78.

[23] D Hao and C Wei. Dynamic characteristic analysis of bi-directional functionally graded Timoshenko beams. Compos. Struc. 2016; 141, 253-63.

[24] SMR Khalili, AA Jafari and SA Eftekhari. A mixed Ritz-DQ method for forced vibration of functionally graded beams carrying moving loads. Compos. Struc. 2010; 92, 2497-511.

[25] SA Eftekhari and AA Jafari. A mixed method for free and forced vibration of rectangular plates. Appl. Math. Model. 2012; 36, 2814-31.

[26] Y Wang and D Wu. Thermal effect on the dynamic response of axially functionally graded beam subjected to a moving harmonic load. Acta Astronautica 2016; 127, 171-81.

[27] C Tao, YM Fu and HL Dai. Nonlinear dynamic analysis of fiber metal laminated beams subjected to moving loads in thermal environment. Compos. Struc. 2016; 140, 410-6.

[28] T Yan, S Kitipornchai, J Yang and XQ He. Dynamic behaviour of edge-cracked shear deformable functionally graded beams on elastic foundation under a moving load. Compos. Struc. 2011; 93, 2992-3001.

[29] HP Lee. The dynamic response of a Timoshenko beam subjected to a moving mass. J. Sound Vib. 1996; 198, 249-56.

[30] E Esmailzadeh and M Ghorashi. Vibration analysis of a Timoshenko beam subjected to a travelling mass. J. Sound Vib. 1997; 199, 615-28.

[31] MA Mahmoud and MAA Zaid. Dynamic response of a beam with crack subject to a moving mass. J. Sound Vib. 2002; 256, 591-603.

[32] K Kiani, A Nikkhoo and B Mehri. Prediction capabilities of classical and shear deformable beam models excited by a moving mass. J. Sound Vib. 2009; 320, 632-48.

[33] M Şimşek. Vibration analysis of a functionally graded beam under a moving mass by using different beam theories. Compos. Struc. 2010; 92, 904-17.

[34] M Şimşek. Dynamic analysis of an embedded microbeam carrying a moving microparticle based on the modified couple stress theory. Int. J. Eng. Sci. 2010; 48, 1721-32.

[35] Y Wang, K Xie and T Fu. Vibration analysis of functionally graded graphene oxide composite beams using a new Ritz - SoltutienSshapldfuhaction Eng. 2020; 42, 180.

[36] Y Wang, K Xie. T Fu and C Shi. Vibration response of a functionally graded graphene nanoplatelet reinforced composite beam under two successive moving masses. Compos. Struc. 2019; 209, 92839.

[37] Y Wang, A Zhou, T Fu and W Zhang. Transient response of a sandwich beam with functionally graded porous core traversed by a non-uniformly distributed moving mass. Int. J. Mech. Mater. Des. 2019; 16, 519-40.

[38] M Şimşek. Some closed-form solutions for static, buckling, free and forced vibration of functionally graded (FG) nanobeams using nonlocal strain gradient theory. Compos. Struc. 2019; 224, 111041.

[39] MAR Loja and JI Barbosa. In-plane functionally graded plates: A study on the free vibration and dynamic instability behaviours. Compos. Struc. 2020; 237, 111905.

[40] YL Lei, K Gao, X Wang and J Yang. Dynamic behaviors of single- and multi-span functionally graded porous beams with flexible boundary constraints. Appl. Math. Model. 2020; 83, 754-76.

[41] M Şimşek and M Al-shujairi. Static, free and forced vibration of functionally graded (FG) sandwich beams excited by two successive moving harmonic loads. Compos. Part B 2017; 108, 18-34. 